THURSDAY, JUNE 19, I 873

\section{FERE.IIIAH HORROX*}

II.

I $T$ is now time to pass to the particular incident which has immortalised the name of Horrox, his observation of the transit of Venus over the sun's disc on November 24,1639 (O.S.) It would have been sufficient for his renown to have been the first witness of the phenomenon, but he had in addition the honour of supplying an omission of Kepler's, who had indeed predicted the transit of 163 I, but had failed to point out the occurrence of another eight years subsequently. The transit of $163 \mathrm{I}$ had not been observed owing to its occurrence at night, and that of 1639 had been foreseen by no one save Horrox, and was watched by no one but himself and his friend Crabtree, whom he apprised of the forthcoming event in a letter dated on the October 26 previous.

We borrow Mr. Whatton's account of the observation ("Life of Jeremiah Horrox," pp. 4t-46).

"After having deliberated on the best method of making the observation, he determined to adnit the sun's image into a dark room, through a telescope properly adjusted for the purpose, instead of receiving it through a hole in the shutter merely, as recommended by Kepler. He considered that by the latter method the delineation would not be so perfect, unless it were taken at a greater distance from the aperture than the narrowness of his apartment would allow; neither was it likely that the diameter of Venus would be so well defined; whereas his telescope, through which he had often observed the solar spots, would enable him to ascertain the diameter of the planet, and to divide the sun's limb with considerable accuracy. Accordingly, having described a circle of about six inches diameter upon a piece of paper, he divided its circumference into $360^{\circ}$, and its diameter into 120 equal parts. .. When the proper time came, he adjusted his apparatus so that the image of the sun should be transmitted perpendicularly to the paper, and exactly fill the circle he had described. From his own calculations he had no reason to expect that the transit would take place, at the earliest, before three o'clock in the afternoon of the 24th, but as it appeared from the tables of others that it might occur somewhat sooner, in order to avoid the chance of disappointment, he began to observe about mid-day on the 23 rd. Having continued to watch with unremitting care for upwards of four-andtwenty hours, excepting during certain intervals of the next day when, as he tells us, he was called away by business of the highest importance, which could not with propriety be neglected, he was at length rewarded for his anxiety and trouble by seeing a large dark round spot enter upon the disc of light."

The "business of the highest importance" was undoubtedly divine service, the transit having taken place on a Sunday. Most modern astronomers of Horrox's profession would, no doubt, have considered the claims of science paramount on an occasion like this. Horrox, in accordance with the feeling of his day, judged otherwise, and when all the circumstances of the case are taken into account, his sacrifice on behalf of what he esteemed a higher duty, must be regarded as an act of extraordinary heroism. He had, it is true, almost convinced himself that the transit could not occur until the afternoon, but even this anticipation was a proof of courageous reliance on his own judgment, being founded on his correction of Kepler's Rudolphine tables, according to the data supplied by which it should have occurred at 8.8 A.M. The phenomenon was also observed by Crabtree, but less perfectly, owing to the cloudy state of the atmosphere at Manchester. A letter from Crabtree on the subject to another north-country astronomer, Gascoigne, contains the remarkable expression, "I do believe there are as rare inventions as Galileo's telescope yet undis. covered."

Horrox did not remain at Hoole much above six months after this great achievement. In July, 1640, we find him again at Toxteth, which he never afterwards left. He must, accordingly, have resigned his curacy, on what account is unknown, as is also the precise nature of his subsequent avocations. We only gather from his correspondence that his affairs were in a very unsettled state, that the duration of his stay at Toxteth was uncertain, and that he was continually called from home. From his complaints of the impossibility of prosecuting his astronomical researches, one would almost surmise that his occupation was nocturnal, especially as he found time for the observations on the tides already referred to. His sustained enthusiasm for astronomy, as well as the generosity of his temper, is touchingly shown in a letter congratulating his friend Crabtree on the success of soms observations reported by him: "Your letter alone," he says, "has enough and more than enough to transport beyond all bounds a soul more master of itself than mine. My emotion and gladness are such as you will more easily understand than I express." Afrer several postponements, he eventually fixes January 4,16 in, for a visit to Broughton, but the intention was frustrated by his sudden death on the morning of the preceding day. We learn this from an endorsement by Crabtree, who gives no particulars respecting the cause of death, and who himself, according to Dr. Wallis, only survived his friend for an extremely short period.

We are indebted to Crabtree for the preserva. tion of Horrox's extant papers, those only having escaped destruction which were obtained by him after the writer's death. Of the remainder, part were destroyed during the Civil Wass; part carried to Ireland by Horrox's brother Jonas, who appears to have shared his scientific tastes, and there lost; another portion, after having aided in the compilation of Jeremiah Shakerley's astronomical tables, was destroyed in the great fire of 1666 . Crabtree's MSS., tappily including the autograph of the "Venus in Sole visa," were purchased after his death by Dr. Worthington, of Emmanuel College, subsequently Vicar of Hackney, and a copy of the "Venus," lent by him to the astronomer Hartlib, having found its way into the hands of Hevelius, was published by the latter in 1662 . The Royal Society, just instituted in England, immediately took cognizance of the remainder of the MSS., and having obtained these from Dr. Worthington, placed them in the hands of Dr. IVallis, Professor of Geometry at Oxford, whose Latin translation was ultimately published in 1674 . By a judicious arrangement of his materials he was enabled to digest these into a perfect treatise, to which he gave the title of "Astronomia Kepleriana Defensa et Promota." To this be added a translation of the scientific portion of 
Horrox's letters to Crabtree, to which we are indebted for most of our scanty biographical information. An inspection of the originals, should these have been preserved would probably contribute much to clear up doubthul points, and to complete our conception of Horrox's intellectual character. The main outlines of the latter, however, are sufficiently apparent. They comprise a marvellous patience and persistency, combined with widereaching activity, a philosophical faculty for generalisation, ambition, enthusiasm, and self-confidence. The versatility of his attainments is attested by the composition of his "Venus" in Latin, by the quotations in his letters from Horace and Juvenal, and by his reference to Raleigh's "History of the World." Of his restless energy and fertility of resource we have proof in the promptitude with which, when debarred from his favourite pursuit, he turns to the investigation of the tides. His grasp of general principles is displayed, among other passages, by a remarkable one in which he speaks of the possibility of illustrating the elliptic orbits of the planets by terrestrial analogies. "To which method of confirmation Kepler is always partial, and most justly, inasmuch as Nature throughout the universe is One, and the general harmony of creation causes the lesser things to be examples of the greater, as the revolution of the moon around the earth is an emblem or imitation of that of the stars around the sun." "We have already had occasion to appreciate his enthusiasm; and the self-reliance usually associated with enthusiasm is powerfully evinced in another letter exhorting Crabtrec to undertake, in conjunction with hin, the preparation of a new set of astronomical tablcs. From some cxpressions in this it may be conjectured that he felt hurt at the ignorant comments of his neighbours, and his resentment against his false guide Lansberg, which occasionally transgresses the limits of what would be considered courtesy at the present day, is another indication of a sensitive spirit. When we add to these traits the self-denial manifested on occasion of the transit, and in the temporary renunciation of his astronomical researches in deference to the claims, as seems probable, of his family, we must recognise in Horrox no mere man of science, but a distinct individuality of-singular force and attractiveness. His precise place in the scientific world must be left to astronomers to determine; it requires, however, no special knowledge of the science to apprehend that the obscure youth who, under every disadvantage, was able to correct Kepler, might, if only he could have continued at Cambridge, icry probably have rivalled him. In him England lost the promise of an astronomer of the first class, which loss, like many a similar one, would have remained absolutely unknown, but for the fortunate conjunction of his name with a phenomenon of regular recurrence and universal interest. If the commemoration of his great achievement cannot be equally universal, it should at least transcend merely local limits. Local patriotism has done its part well; an appropriate memorial has been erected in the church at Hoole, and we are exceedingly indebted to Mr. Whatton for his intelligent memoir and valuable translation of the "Venus in Sole visa." More, however, is demianded, and it would redound to the credit of Horrox's countrymen if, on the December day of 1874 , when English watchers scan the skics of another hemisphere for the transit of Venus, Englishmen at home were found dedicating a national monument to the first observer of the phenomenon in this.

\section{AGOK'S "PHILIPPINE ISLANDS"}

Reisen in den Philippinen, von F. Jagor. Mit zahlreichen Abbildungen und einer Karte. (Berlin: IVeidmannsche Buchnandlung. 1873.)

THE increasing importance which the Philippines are assuming in both English and American commerce, the comparative insufficiency of the information we possess concerning them, and the beauty and productiveness of nearly the whole region, amply justify the ardour with which the author of this volume has devoted himself to a thorough exploration of the group, and an cxhaustive study of every feature of interest appertaining to its component islands and their population. In this very interesting and acceptable work he has given to the world the results of his observation and inquiries, and of these it may be said that, while in point of extent and variety they are suffciently comprehensive to embrace within their limits every subject of interest or of practical importance to which we should expect to find a place assigned in a book of travels having any pretensions to completeness, they bear the evident impress of the patient, laborious research, and the careful examination and weighing of facts, for which his countrymen are famous.

M. Jagor can hardly be said to be a recent traveller in these islands. His journey through them was made in the years 1859 and 1860 , but unforeseen circumstances put a sudden stop to it; and though fully intending to resume it at a later day, that purpose has not yet been accomplished. Although it must be admitted, therefore, that his work does not make its appearance with all that absolute freshness about it to which we are accustomed in these days of ocean steam-navigation, the apparently long interval which has elapsed since his visit has been profitably turned to account by him in the carcful study of an immense mass of materials accumulated by himself during his stay, or which he obtained through the Spanish Colonial Minister, or found in the great national libraries of London and Berlin, including a few bulky monkish chronicles, the perusal of which last was a work both long and tedious. In the vast labour incident to the extraction from these various sources of their most important and most interesting details, he has been sustained by a conviction that his subject was worthy of it. He has felt, as he tells us, that few countries in the whole world are so little known or so seldom visited as the Philippines, while none present more agreeable attractions for the traveller, or have been more profusely endowed by the hand of Nature, or contain a larger store of neglected treasure for the natural historian. So strong and so abiding is his faith on this last point, he gravely assures his readers, that even poor travellers would amply cover the cost of their journey by the sale of their collections. Without going so far as to endorse this suggestion in its full and entire significance, it is nevertheless true that the descriptions here given constitute, in the aggregate, a picture of marvellous natural 